\title{
Eksplorasi Etnomatematik Batik Sukapura
}

\author{
Eva Mulyani $^{1^{*}}$ dan Ike Natalliasari ${ }^{2}$ \\ 1*,2Program Studi Pendidikan Matematika, Universitas Siliwangi \\ Jalan Siliwangi No. 24, Tasikmalaya, Jawa Barat, Indonesia \\ 1*evamulyani@unsil.ac.id,2ikenatalliasari@unsil.ac.id
}

Artikel diterima: 30-10-2019, direvisi: 29-01-2020, diterbitkan: 31-01-2020

\begin{abstract}
Abstrak
Melihat potensi batik Sukapura yang memiliki jenis batik dan motif khas yang keberadaannya diwariskan dari generasi ke generasi, hingga generasi sekarang, ditambah dengan kajian etnomatematika yang mengeksplorasi konsep geometri sebelumnya. Penelitian ini bertujuan untuk mengungkapkan konsep matematika yang terdapat pada aktivitas membatik dan konsep matematika yang terdapat pada motif batik tulis Sukapura. Metode yang digunakan adalah penelitian etnografi dan bersifat eksploratif. Teknik pengumpulan data dilakukan yaitu dengan observasi partisipasi pasif, wawancara tak terstruktur, dokumen, dan keabsahan data berdasarkan triangulasi data. Instrumen penelitiannya adalah peneliti sendiri. Pemilihan sumber data dilakukan secara purposive bertempat di Desa Sukapura. Teknik analisis data melewati tahap reduksi data, penyajian data, penarikan kesimpulan dan verifikasi. Hasil penelitian menunjukkan bahwa terdapat konsep matematika pada aktivitas membatik dan selain konsep geometri bidang datar ternyata terdapat konsep transformasi geometri, yaitu: 1) Diagram pada tahapan-tahapan proses membatik berisi model matematika; 2 ) pada batik tulis Sukapura motif Daun Picis memiliki simetri refleksi, dan dua simetri putar/rotasi pada sumbu yang berpotongan; 3) pada batik tulis Sukapura motif Kolentang memiliki simetri translasi, tidak memiliki simetri refleksi dan tidak memiliki simetri rotasi.

Kata Kunci : batik tulis sukapura, eksplorasi, etnomatematika, konsep matematika.
\end{abstract}

\section{The Exploration of the Batik Sukapura Ethnomathematics}

\begin{abstract}
Seeing the potential of Sukapura batik, which has unique types of batik and motifs whose existence has been passed down from generation to generation, to the present generation, coupled with ethnomatematics studies exploring previous geometry concepts. This study aims to reveal the mathematical concepts contained in the batik activity and mathematical concepts contained in the Sukapura written batik motif. The method used is ethnographic research and is exploratory in nature. Data collection techniques were carried out by passive participation observation, unstructured interviews, documents, and data validity based on data triangulation. The research instrument is the researcher himself. The selection of data sources was done purposively at Sukapura Village. Data analysis techniques pass the stages of data reduction, data presentation, drawing conclusions and verification. The results showed that there are mathematical concepts in batik activity and in addition to the concept of flat plane geometry there are the concepts of geometry transformation, namely: 1) Diagrams at the stages of the batik process containing mathematical models; 2) on Sukapura batik, the Picis Leaf motif has a reflection symmetry, and two rotating/rotational symmetries on the intersecting axis; 3) in Sukapura batik, the Kolentang motif has translational symmetry, no reflection symmetry, and no rotational symmetry.

Keywords: Sukapura written batik, exploration, ethnomathematics, mathematical concepts.
\end{abstract}




\section{Pendahuluan}

Sejak UNESCO menetapkan dan mengakui keberadaan batik sebagai warisan budaya dunia pada tanggal 2 Oktober 2009, keberadaan batik semakin berkembang pesat khususnya di daerah Tasikmalaya. Daerah penghasil batik di Tasikmalaya Salah satunya adalah daerah Sukapura yang berada di kecamatan Sukaraja kabupaten Tasikmalaya. Supriono (2016) menyatakan bahwa Batik yang dihasilkan oleh daerah Sukapura merupakan salah satu peninggalan budaya pada masa Kerajaan Tarumanegara yang area pemerintahannya berpusat di Sukapura.

Berdasarkan studi pendahuluan bahwa batik Sukapura terdiri dari batik tulis dan batik cap. Pada awalnya meskipun dalam perkembangannya batik sukapura mendapat pengaruh dari batik keraton (Jawa Tengah) dan Cirebon, batik Sukapura tetap merupakan batik tulis yang memiliki karakter cukup kuat. Segi warna dan motif merupakan dua hal yang membedakan antara batik Sukapura dengan batik-batik dari daerah lain. Pada umumnya warnawarna batik tulis yang dihasilkan di daerah Sukapura menggunakan warna-warna indigo dan soga yaitu warna hitam, coklat, marun, putih, dan gading. Batik tulis sukapura yang mempunyai ciri khas dalam ketahanan warna yang relatif awet dan tidak cepat pudar, bahkan semakin dicuci akan semakin kuat warnanya. Batik tulis Sukapura terkenal juga dengan hiasan flora dan faunanya. Hiasan tersebut mencerminkan bahwa lingkungan Sukapura berada di daerah tanah sunda.

Motif batik tulis Sukapura banyak yang menunjukkan beragam konsep-konsep matematika diantaranya garis sejajar, simetri, lingkaran, persegipanjang, persegi, belah ketupat, segi tiga, sudut siku-siku dan lain sebagainya. Hanya saja dimungkinkan mereka tidak mengetahui jenis-jenis geometri yang digunakan. Salah satu cara mempelajari matematika yaitu dengan cara memperoleh konsep matematika dari lingkungan sosial budaya (Afriansyah, 2012), sehingga matematika dapat dipelajari lebih mudah oleh masyarakat. Ketika matematika, budaya, dan pendidikan dikombinasikan maka kombinasi tersebut dinamakan ethnomathematics (Van De Walle, 2008).

Etnomatematika merupakan matematika yang dipraktikkan oleh kelompok budaya seperti masyarakat perkotaan dan pedesaan, kelompok buruh, anak-anak dari kelompok usia tertentu, masyarakat lainnya (Budiarto, 2015). Penelitian yang dilakukan oleh Dewita, Mujib, dan Siregar (2019) menunjukkan hasil eksplorasi dan analisis ornamenornamen Bagas Godang ditemukan adanya konsep matematika berupa konsep grup, geometri dan trasformasi geometri dan komposisinya. Penelitian yang dilakukan oleh Zayyadi (2017) hasilnya menunjukkan bahwa garis lurus, garis lengkung, garis sejajar, simetri, titik, sudut, persegi panjang, segitiga, lingkaran, jajargenjang dan konsep kesebangunan merupakan 
konsep-konsep matematika yang terdapat pada motif Batik Madura.

Melihat potensi batik Sukapura yang memiliki jenis batik dan motif khas yang keberadaannya diwariskan dari generasi ke generasi, hingga generasi sekarang, ditambah dengan kajian etnomatematika yang mengeksplorasi konsep geometri sebelumnya, maka dalam artikel ini akan dibahas tentang "Eksplorasi Etnomatematika Batik Sukapura".

Penelitian ini bertujuan untuk mengetahui konsep matematika yang terdapat dalam aktivitas membatik pada Batik Tulis Sukapura Tasikmalaya dan mengetahui konsep matematika lainnya yang terdapat pada motif Batik Tulis Sukapura Tasikmalaya selain geometri bidang seperti lingkaran, persegi, persegipanjang, segitiga, belah ketupat, simetri, garis sejajar, sudut siku-siku dan lain sebagainya

Penellitian ini diharapkan dapat menjadi referensi bagi peneliti lain yang tertarik pada etnomatematika untuk mengungkapkan konsep matematika yang terdapat dalam budaya. Diharapkan juga penelitian ini dapat mengubah pandangan keliru masyarakat bahwa matematika bebas dari budaya sehingga dapat lebih memahami bahwa matematika banyak terdapat dalam aktivitas kehidupan (Afriansyah, 2019), tidak hanya menjadi sesuatu yang kaku dalam proses pembelajaran matematika. Selain itu, matematika dapat dirasakan manfaatnya oleh masyarakat luas (Ridia \& Afriansyah, 2019).

\section{Metode}

Sugiyono (2016) mengemukakan bahwa penelitian yang dilakukan di lapangan dengan kondisi yang sebenarnya (alamiah) disebut sebagai penelitian dengan metode etnografi, hal ini dikarenakan awal penggunaan metode ini untuk penelitian di bidang antropologi budaya dengan analisis bersifat kualitatif. Selanjutnya Spradley (2006) mengatakan bahwa etnografi merupakan penelitian lapangan yang bersifat thick description, holistikintegratif, dan analisis kualitatif melalui proses wawancara dan observasi. Penelitian etnomatematika ini menggunakan pendekatan kualitatif, yang menurut Sugiyono (2016) bahwa pendekatan kualitatif dilakukan apabila akan meneliti keadaan lapangan (alamiah), dengan tidak membuat perlakuan, sehingga data yang terkumpul berdasarkan sumber data yang ada.

Metode etnografi merupakan metode yang mendukung penelitian etnomatematika. Dalam penelitian ini, kepustakaan dan observasi serta wawancara digunakan untuk menggali informasi dari beberapa warga pengrajin batik tulis di daerah desa Sukapura Kabupaten Tasikmalaya. Dikarenakan penelitian ini bertujuan untuk memperoleh informasi mengenai matematika dalam perspektif budaya 
maka digunakanlah penelitian deskriptif kualitatif.

Penelitian ini bertempat di desa Sukapura Kecamatan Sukaraja Kabupaten Tasikmalaya. Pelaku adalah para pengrajin batik Sukapura yang memenuhi lima syarat minimal. Menurut Spradley (2006), terdapat 5 syarat minimal dalam pemilihan informan yang baik, yakni enkulturasi penuh, Keterlibatan langsung, Suasana budaya yang tidak dikenal, Waktu yang cukup, Non-analitis. Dalam penelitian ini pengrajin batik tulis Sukapura sebagai informan menjawab semua pertanyaan peneliti melalui wawancara dan melakukan aktivitas membatik dari awal sampai akhir.

Hal yang paling strategis dalam penelitian yaitu teknik pengumpulan data (Puspitasari, dkk., 2019). Hal ini sangat penting untuk dikuasai dikarenakan tujuan dari meneliti adalah mendapatkan data, sehingga tanpa mengetahui teknik tidak akan memenuhi standar yang ditetapkan (Mardiani, 2019). Metode etnografi digunakan dalam penelitian ini. Spradley (2006) mengatakan bahwa untuk mendokumentasikan suasana budaya yang dipelajari digunakan catatan etnografis yang gambar, alat perekam, catatan lapangan dan benda-benda lain.

Observasi. Menurut Hadi (Sugiyono, 2016) bahwa observasi merupakan suatu proses yang tersusun dari pelbagai proses biologis dan psikologis, yang terpenting yaitu proses-proses pengamatan dan ingatan. Teknik pengumpulan data pada penelitian etnomatematika ini menggunakan observasi penelitian yang berkenaan dengan proses kerja yang dilakukan informan. Teknik observasi yang digunakannya adalah observasi partisipasi pasif, Sugiyono (2016) mengemukakan bahwa dalam hal ini peneliti datang ke tempat kegiatan yang diamati, tetapi tidak ikut terlibat dalam kegiatan tersebut, namun data yang diperoleh akan lebih lengkap, tajam dan mengetahui pada tingkat makna dari setiap perilaku yang tampak.

Dalam penelitian ini digunakan teknik wawancara tak terstruktur. Dengan garis besar pertanyaan yang diajukan yaitu: bahan yang digunakan untuk membuat batik tulis, alat yang digunakan dalam pembuatan batik tulis, motif-motif yang terdapat dalam batik tulis Sukapura, filosofi dari motif batik tulis Sukapura, proses atau langkah-langkah pembuatan batik, waktu yang dibutuhkan untuk menghasilkan sebuah batik.

Dokumen. Dokumen yang didapatkan dalam penelitian ini berupa catatan harian, sejarah kehidupan, cerita, foto, dan karya batik yang dihasilkan oleh pengrajin batik tulis Sukapura. Dalam penelitian etnomatematika ini, peneliti melakukan penulisan catatan harian dari hasil coretan selama dilakukannya observasi dan wawancara dengan informan mengenai batik tulis sukapura yang disusun menjadi suatu dokumen.

Teknik analisis data yang dilakukan mengacu pada model Miles and 
Huberman (Sugiyono, 2016), yang terdiri dari Data Reduction (Reduksi Data), Data Display (Penyajian Data), dan Conclusion Drawing/verification.

Data Reduction yaitu data yang diperoleh harus dicatat secara teliti dan rinci, karena dari lapangan cukup banyak.

Data Display yaitu penyajian data dilakukan dalam bentuk uraian singkat, menggunakan bagan, hubungan antar kategori, flowchart dan sejenisnya. Miles dan Huberman (Sugiyono, 2016) menyatakan bahwa teks yang bersifat naratif paling sering digunakan untuk menyajikan data dalam penelitian kualitatif.

Conclusion Drawing/ verification, yaitu kesimpulan awal dalam penelitian kualitatif masih bersifat sementara. Untuk mendapatkan data yang tepat, kesimpulan yang didapatkan harus diverifikasi selama penelitian berlangsung.

\section{Hasil dan Pembahasan}

\section{A. Hasil Penelitian}

Narasumber dalam penelitian ini yaitu Informan $1\left(I_{1}\right)$ dan Informan $2\left(I_{2}\right)$ yang merupakan pengrajin batik di Desa Sukapura, untuk lebih tepatnya di Kp. Pasarkolot RT/RW 11/04 Desa Sukapura Kecamatan Sukaraja Kabupaten Tasikmalaya. Informan menebutkan bahwa kerajinan Batik di Desa Sukapura merupakan hasil turun-temurun dari nenek moyang semasa kejayaan Bupati Wiradadaha atau biasa disebut abdi dalem sawidak Sukapura pada tahun 1800an
Masehi. Kain batik tulis pada masa itu hanya dibuat dan digunakan oleh para menak abdi dalem sehingga tidak sembarang orang bisa menggunakan kain batik sebagai pakaian, dan tidak semua orang bisa memproduksi kain batik.

\section{Data Hasil Catatan Lapangan}

Berdasarkan pemaparan informan bahwa Batik Sukapura memiliki 2 jenis batik berdasarkan teknis pembuatannya yaitu batik batik tulis dan batik cap. Peneliti melakukan penelitian pada Batik Tulis Sukapura, yaitu bagaimana aktivitas membatik yang terdapat pada batik tulis Sukapura (lihat tabel 1).

Motif batik sukapura berdasarkan tabel 1 ada 2 motif yaitu motif daun Picis dan motif Kolentang

\section{a. Proses Pembuatan Batik Tulis}

Proses membuat batik tulis Sukapura ini memiliki beberapa tahapan pengerjaan sehingga dihasilkan batik tulis khas Sukapura, yaitu sebagai berikut: Pemotongan kain, kain boeh dipotong dengan ukuran 2,5 x 1,15 meter. Kain ini biasa disebut kain samping. Diketel, yaitu kain boeh diremas dan direndam dalam minyak kacang dengan ukuran sebanyak

Tabel 1.

Motif Batik Tulis Sukapura

\begin{tabular}{|c|c|c|}
\hline No & Nama & Gambar \\
\hline 1. & $\begin{array}{l}\text { Motif Daun } \\
\text { Picis }\end{array}$ & $\begin{array}{l}\text { - } \\
\text { - }\end{array}$ \\
\hline 2. & $\begin{array}{l}\text { Motif } \\
\text { Kolentang }\end{array}$ & 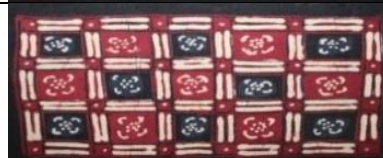 \\
\hline
\end{tabular}


0,5 kg. Selanjutnya kain direndam dalam campuran air soda abu merang/sapu pare, dan cituar untuk menghilangkan kelebihan minyak. Ukuran masing-masing bahan pada saat pengketelan yaitu sebanyak 100-120 gr soda abu, dan 600 cc cituar. Banyak kain untuk setiap pengketelan adalah 12 lembar kain samping.

Diibun, yaitu kain boeh setelah diketel, secara berulang-ulang kain diuleni dan dijemur. Selama 2 minggu kegiatan ini dilakukan berulang-ulang dengan terlindung dari cahaya matahari hingga kain menjadi kering. Kemudian kain disimpan diatas kayu dan dipukul-pukul dengan pemukul kayu untuk dilicinkan. Kegiatan ini dilakukan agar kain menjadi lemas, sehingga daya serap kain terhadap bahan pewarna atau zat lebih tinggi dan kuat.

Dilorot, yaitu kain boeh di rendam pada air mendidih, lalu dicuci dengan air biasa. Dikanji, yaitu kain boeh dibilas pada campuran air dengan tepung kanji. Ukuran masing-masing bahan untuk pengkanjian yaitu 2 Liter air dengan 1,5 ons tepung kanji. Banyak kain untuk sekali pengkanjian yaitu sebanyak 16 lembar kain samping. Setelah proses pengkanjian kain boeh dijemur hingga kering. Pengkanjian dilakukan agar tekstur kain lebih halus dan rapat atau padat sehingga kualitas kain boeh yang dihasilkan semakin baik untuk dibuat batik. Direngreng, yaitu kain boeh di serat/ ditulis dengan pola dan motif yang akan dimaksudkan pada kain batik.
Pada saat pembuatan pola batik, pengrajin menggunakan pensil untuk melakukan taksiran ukuran pada pola tersebut. Sedangkan untuk pembuatan motif batik, pengrajin secara langsung menggunakan canting pada proses serat. Biasanya Kegiatan membatik diawali dengan menggambar garis-garis diluar pola dan isen-isen untuk mengisi pola dengan berbagai ornamen atau ragam hiasan yang dimaksudkan. Ada istilah nyecek Pada pembuatan isen-isen, yaitu membuat isian dengan cara memberi titiktitik (nitik) dalam pola yang sudah dibuat. Istilah lainnya yaitu nyawut, dengan cara memberi garis-garis dalam pola yang sudah dibuat.

Kegiatan membatik dimulai dengan cara mengambil malam atau lilin cair menggunakan canting sedikit demi sedikit. Agar malam tidak terlalu panas, tiup-tiup sebentar kemudian goreskan canting mengikuti pola untuk membentuk motif yang akan dibuat. Apabila malam sampai menetes pada permukaan kain selain pola maka akan mempengaruhi kesempurnaan motif batik yang dihasilkan. Kegiatan selanjutnya adalah nerusan yaitu dengan menorehkan malam pada sisi kain sebaliknya. Itulah sebabnya batik tulis memiliki gambaran yang terang antara bagian depan dan bagian belakang kain.

Ditembok, yaitu menebalkan pola dan motif batik yang telah direngreng dengan lilin malam menggunakan canting panembong atau golonggong. Proses penembokkan dilakukan untuk menutupi 
atau membuat blok atau mengisi bidang pada sebuah pola motif batik yang tidak boleh terkena warna dasar pada saat dilakukan proses pewarnaan. Bagian tersebut haruslah ditutup dengan lapisan malam yang tebal seolah-olah seperti membuat tembok sebagai penahan. Medel atau Pewarnaan I, yaitu kain boeh melalui proses pewarnaan tahap I, yakni untuk mendapatkan warna dasar biru/indigo. Campuran larutan warna dasar tersebut adalah serbuk BO, soda api, dan warna biru. Ukuran masing-masing bahan berurutan sebanyak $10 \mathrm{gr}, 5 \mathrm{gr}$, dan 20 gr. Campuran bahan tersebut di masukkan ke dalam air secukupnya, sehingga kain dapat dicelupkan pada bak warna yang telah diberi larutan pewarna. Setelah pewarnaaan selesai, kain ditiriskan hingga mengering.

Dipopog, yaitu proses menghilangkan lilin malam yang menempel pada kain. Mopog ini dilakukan dengan cara mencelup-celupkan kain kedalam air mendidih. Dibiron, yaitu proses penjemuran setelah dipopog, kemudian kain untuk kedua kalinya melalui proses dikanji, diserat, dan ditembok kembali sehingga kain dapat dilanjutkan pada proses pewarnaan ke II. Kegiatan mem bironi ini, yaitu menutupi warna biru dan isen-isen pola pada kain batik dengan menggunakan malam, kemudian menulisi kembali untuk mengisi bagian kain yang belum diwarnai dengan motif yang dimaksudkan sehingga akan dilakukan proses pewarnaan selanjutnya. Nyoga atau
Pewarnaan II, yaitu proses pemberian warna tahap II, yakni untuk mendapatkan warna merah maroon/ warna soga. Campuran larutan warna nyoga tersebut adalah sebruk BO, soda api, dan warna merah. Ukuran masing-masing bahan berurutan sebanyak 10 gr, 5 gr, dan 20 gr. Campuran bahan terssebut di masukkan ke dalam air 0,5 Liter, sehingga kain dapat dimasukkan dalam bak warna yang telah diberi larutan pewarna.

Sebelum pewarnaan, kain dilipat menjadi lima lipatan agar memudahkan proses pewarnaan. Setelah pewarnaaan selesai, kain ditiriskan hingga mengering dibawah sinar matahari. Nyaren, yaitu pemberian zat penguat warna pada kain yang telah melalui semua proses pewarnaan, sehingga warna kain batik tidak mudah pudar. Dalam proses ini kain batik disikat dengan larutan GG (penguat warna) sebanyak 20 gr. Finishing, yaitu kain batik dipopog kembali dengan cara mencelupkan kain ke dalam air mendidih dalam gerengseng untuk menghilangkan sisa-sisa lilin malam yang masih terdapat pada kain. Setelah kain ditiriskan, kain dicuci kembali dengan larutan tepung kanji kemudian dikeringkan. Proses terakhir, sebelum kain batik tulis Sukapura dikemas dan dipasarkan, maka kain dicuci dengan air bersih dan diangin-anginkan hingga kering.

\section{b. Alat untuk membuat Batik Tulis Sukapura \\ Berdasarkan hasil wawancara tak} terstruktur, bahwa dalam pembuatan 
batik terdapat peralatan yang memudahkan mengangkat dan digunakannya, yaitu canting, kompor, menurunkan dari kompor. Lilin malam wajan, lilin malam, gawangan atau merupakan lilin yang khusus digunakan wangkring, saringan, kain mori atau kain boeh, jojodog, ember atau wadah besar, alas atau taplak, gerengseng, bak pewarnaan, timbangan, dan zat pewarna batik.

Canting merupakan alat utama yang digunakan untuk membuat batik tulis, fungsinya seperti pena yaitu untuk mengambil lilin/malam dan menggambarkannya pada kain. Canting terbuat dari bahan kuningan atau tembaga, gagangnya terbuat dari kayu, ukurannya bermacam-macam sesuai besar kecilnya garis gambar yang akan dibuat. Kompor merupakan peralatan membatik fungsinya untuk memanaskan wajan/ penggorengan yang berisi bahan-bahan yang akan digunakan dalam membatik. Kompor yang digunakan biasanya kompor yang menggunakan bahan bakar minyak. Namun, ada juga yang menggunakan kompor gas kecil, anglo dengan bahan bakar arang.

Wajan atau penggorengan digunakan sebagai tempat untuk mencairkan lilin agar tetap encer. Lilin fungsinya sebagai tinta untuk membuat gambar pada kain. Canting tidak dapat mengambil lilin, bila lilin malam mengeras. Lilin harus selalu berada diatas wajan agar tetap panas dan cair sehingga tidak membuat cucuk canting tersumbat. Wajan ini biasanya terbuat dari logam atau tanah liat, yang dilengkapi dengan pegangan untuk untuk membatik dalam proses mencanting. Lilin ini berfungsi untuk menutupi motif yang telah dibuat pada kain sehingga menghasilkan corak batik dengan warna yang menarik. Jenis-jenis lilin malam yang digunakan untuk membatik diantaranya malam biron, malam carikan, malam remukan, dan malam tembokan.

Gawangan atau Wangkring merupakan peralatan membatik yang berbentuk seperti gawang dan biasanya terbuat dari kayu atau bambu. Gawangan fungsinya untuk menyampirkan atau membentangkan kain yang akan dibatik. Saringan merupakan peralatan membatik yang digunakan untuk menyaring cairan lilin agar tidak menggumpal, tetap encer, dan bersih. Jojodog atau dudukan yang diperlukan sebagai tempat duduk oleh pengrajin batik pada saat proses membatik, biasanya terbuat dari kayu, bambu, besi, dan plastik.

Ember atau wadah besar yang biasa digunakan pada proses pencelupan dan pewarnaan kain. Alas atau taplak merupakan peralatan yang biasa digunakan untuk alas saat mencanting, alas ini terbuat dari karung sehingga tidak menimbulkan panas ketika lilin malam menetes. Cara pemakaiannya yaitu dengan menutupkan kain alas diatas paha pengrajin. Gerengseng, merupakan peralatan membatik yang digunakan untuk 
Tabel 2.

Aktivitas Matematika pada Proses Membatik Batik Tulis Sukapura

\begin{tabular}{|c|c|c|}
\hline No & $\begin{array}{c}\text { Aktivitas } \\
\text { Matematika }\end{array}$ & Proses Membatik \\
\hline 1. & $\begin{array}{l}\text { Aktivitas } \\
\text { Membilang }\end{array}$ & $\begin{array}{l}\text { Proses pemotongan kain, terdapat penggunaan sistem bilangan untuk } \\
\text { mengukur pemotongan kain. } \\
\text { Proses pengkanjian, terdapat penggunaan sistem bilangan pada ukuran } \\
\text { bahan-bahan untuk pengkanjian. } \\
\text { Proses pengketelan, terdapat penggunaan sistem bilangan pada ukuran } \\
\text { bahan-bahan untuk pengketelan. }\end{array}$ \\
\hline 2. & $\begin{array}{l}\text { Aktivitas } \\
\text { Mengukur }\end{array}$ & $\begin{array}{l}\text { Proses pemotongan kain, terdapat pengukuran satuan panjang. } \\
\text { Proses pengketelan, terdapat pengukuran satuan volume, berat, dan } \\
\text { kuantitas. } \\
\text { Proses pengibunan, terdapat pengukuran satuan waktu. } \\
\text { Proses pengkanjian, terdapat pengukuran satuan volume, berat dan } \\
\text { kuantitas. } \\
\text { Proses pewarnaan, terdapat pengukuran satuan berat dan volume. } \\
\text { Proses perengrengan, terdapat pengukuran satuan panjang. } \\
\text { Proses penyarenan, terdapat pengukuran satuan berat dan volume. }\end{array}$ \\
\hline 3. & $\begin{array}{l}\text { Aktivitas } \\
\text { Melokasikan }\end{array}$ & $\begin{array}{l}\text { Proses perengrengan, terdapat penggunaan titik, garis, dan jarak pada pola } \\
\text { rancangan motif batik seperti pada sistem kordinat. } \\
\text { Proses penembokan, terdapat penggunaan suatu bidang dua dimensi pada } \\
\text { saat membuat blok pada motif batik. }\end{array}$ \\
\hline 4. & $\begin{array}{l}\text { Aktivitas } \\
\text { Merancang }\end{array}$ & $\begin{array}{l}\text { Proses perengrengan, terdapat dasar-dasar konsep geometri yaitu } \\
\text { penggunaan titik, garis, sudut, dan bidang. }\end{array}$ \\
\hline 5. & $\begin{array}{l}\text { Aktivitas } \\
\text { Menjelaskan }\end{array}$ & Proses membatik sehingga memenuhi konsep matematika. \\
\hline
\end{tabular}

mopog, yaitu merebus kain untuk menghilangkan lilin malam.

Bak pewarnaan, merupakan perlengkapan membatik sebagai tempat yang digunakan untuk memberikan campuran warna pada kain. Timbangan, merupakan alat untuk mengukur bahanbahan yang akan digunakan pada pencampuran bahan pembuatan batik, seperti warna. Zat pewarna batik dan zat penguat warna. Zat pewarna batik yang digunakan pada batik tulis sikapura yaitu warna merah (soga) dan biru (indigo). Zat penguat warna digunakan untuk menguatkan warna pada kain batik sehingga tidak mudah pudar.

\section{B. Pembahasan Hasil Penelitian}

Aktivitas matematika yang terdapat pada proses membatik Batik Tulis Sukapura, disajikan pada tabel 2.

Selanjutnya akan diungkapkan konsep Geometri Transformasi yang terdapat pada Motif Batik Tulis Sukapura Tasikmalaya. Berdasarkan pemaparan informan bahwa motif batik tulis Sukapura mempunyai banyak ragam motif. Namun, artikel ini hanya mengungkap beberapa motif batik yang dianggap mempunyai konsep matematika yang mengacu pada penelitian Audun Holme dari Department of Mathematics University of Bergen dalam bukunya yang berjudul "Geometry 
Our Culture Heritage" (second edition) dan diterbitkan pada tahun 2010. Peneliti akan mencoba mengungkapkan konsep matematika geometri simetri yang terdapat pada motif batik tulis Sukapura Tasikmalaya. Berikut adalah contoh motif batik tulis Sukapura yang memiliki bentuk simetri tipe $W_{2}^{2}$, bentuk diperoleh dengan memperbesar kelompok persegi panjang tipe $\quad W_{2} \quad$ yang memiliki pencerminan/refleksi, dan dua simetri putar/rotasi pada sumbu yang berpotongan. Bentuk simetri tipe $W_{2}^{2}$ ini ditemukan pada batik tulis Sukapura motif daun picis (lihat gambar 1 ).

Pada motif daun picis yang memiliki pola bulatan mirip dengan daun picis. Motif ini melambangkan empat penjuru yang berarti sebagai seorang pemimpin harus mampu menjaga keseimbangan dalam kehidupannya, mampu mengendalikan hawa nafsu, dan menjaga kemurnian hati nurani.

Motif daun picis tersebut terlihat adanya transformasi geometri yaitu refleksi atau pencerminan (lihat gambar 2).

Ambil sembarang motif daun picis kemudian direfleksikan terhadap garis $k$ sehingga menghasilkan dua bentuk yang mengawetkan ukuran, memetakan garis menjadi garis, dan mengawetkan kesejajaran. Motif daun picis direfleksikan $\left(M_{k}\right)$ memenuhi sifat yang terdapat pada bentuk simetri tipe $W_{2}^{2}$ yaitu direfleksikan terhadap garis (hijau) yang melewati sebuah ordinat.
Selanjutnya, motif batik tulis Sukapura yang memiliki bentuk $W_{1}$ Bentuk ini hanya memiliki simetri translasi, tidak memiliki simetri refleksi, dan tidak memiliki simetri rotasi. Bentuk simetri tipe $W_{1}$ ditemukan pada batik tulis Sukapura motif kolentang (lihat gambar 3).

Pada motif kolentang tersebut terlihat bahwa terdapat suatu persegi yang menunjukkan adanya transformasi geometri yaitu translasi (lihat gambar 4).

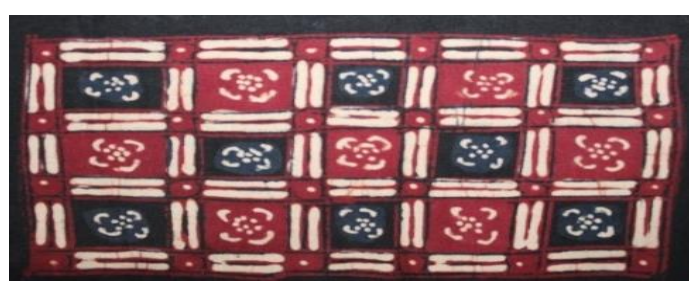

Gambar 1. Batik Tulis Motif Daun Picis.
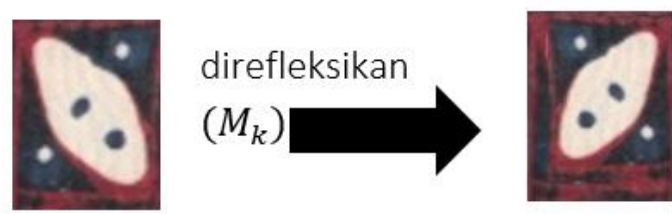

Gambar 2. Ilustrasi Pencerminan Motif Batik Daun Picis.

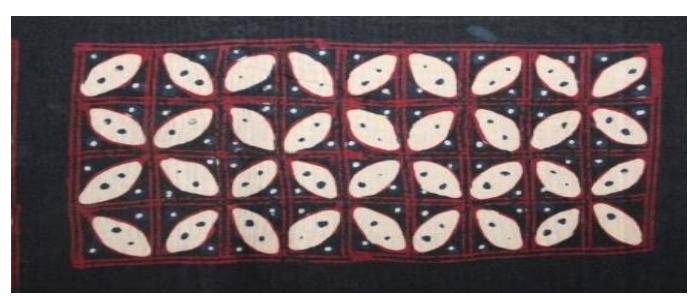

Gambar 3. Batik Tulis Motif Kolentang.

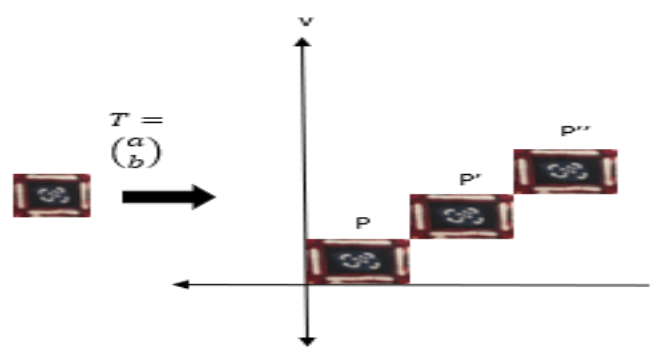

Gambar 4. Ilustrasi Translasi Motif Kolentang. 
Ambil sembarang motif Kolentang kemudian ditranslasikan sebanyak $T=$ $\left(\begin{array}{l}a \\ b\end{array}\right)$. Seperti pada teorema, "setiap pencerminan pada garis merupakan suatu involusi" yang mempunyai definisi "suatu transformasi yang balikannya adalah transformasi itu sendiri disebut involusi". Sehingga translasi dapat memetakan garis menjadi garis, mengawetkan ukuran, dan mengawetkan kesejajaran. Motif Kolentang ditrasnslasikan sebanyak $T=$ $\left(\begin{array}{l}a \\ b\end{array}\right)$ memenuhi sifat yang terdapat pada bentuk simetri tipe $W_{1}$ yaitu memiliki simetri translasi, tidak memiliki simetri refleksi, dan tidak memiliki simetri rotasi.

Motif Kolentang memiliki bentuk simetri tipe $W_{1}$ yaitu translasi, akan dibuktikan dalam konsep aljabar, sebagai berikut.

Misalkan persegi $\mathrm{P}$ adalah persegi $\mathrm{ABCD}$, yang mempunyai titik $A(x, y), B(x, y), C(x, y), \quad$ dan $\quad D(x, y)$ kemudian ditranslasikan oleh $T=\left(\begin{array}{l}a \\ b\end{array}\right)$ sehingga menghasilkan bayangan persegi $P^{\prime}$ adalah persegi PQRS, sehingga mempunyai titik-titik $P(x+a, y+$ b), $Q(x+a, y+b), R(x+a, y+b)$, dan $S(x+a, y+b)$.

\section{Penutup}

Konsep geometri yang terdapat dalam motif batik Sukapura selain konsep geometri bidang datar adalah geometri transformasi. konsep geometri transformasi yang terdapat dalam motif batik Sukapura diantaranya yaitu, bentuk simetri tipe $W_{2}^{2}$ ditemukan pada batik tulis Sukapura motif Daun Picis. Bentuk ini memiliki simetri refleksi, dan dua simetri putar/rotasi pada sumbu yang berpotongan yaitu pada kordinat absis dan ordinat. Bentuk simetri tipe $W_{1}$ ditemukan pada batik tulis Sukapura motif Kolentang. Bentuk ini hanya memiliki simetri translasi, tidak memiliki simetri refleksi, dan tidak memiliki simetri rotasi.

Peneliti selanjutnya diharapkan mengungkap tentang hal-hal yang belum terungkap dalam penelitian ini. Misalnya mengungkap tentang konsep-konsep matematika yang ada kaitannya dengan proses perencaan produksi batik sampai pemasaran produk sehingga mendapatkan keuntungan yang maksimal.

\section{DAfTAR Pustaka}

Afriansyah, E. A. (2012). Design Research: Konsep Nilai Tempat pada Penjumlahan Bilangan Desimal. Tesis yang tidak dipublikasikan berasal dari Beasiswa DIKTI dengan program IMPoME (International Master Program on Mathematics Education). Universitas Sriwijaya PalembangUniversitas UTRECHT Belanda.

Afriansyah, E. A., Puspitasari, N., Luritawaty, I. P., Mardiani, D., \& Sundayana, R. (2019). The analysis of mathematics with ATLAS.ti. Journal of Physics: Conference Series, 1402(7), 077097. 
Budiarto, M. T. (2016). Peran Matematika dan Pembelajarannya Dalam Mengembangkan Kearifan Budaya Lokal Mendukung Pendidikan Karakter Bangsa. Prosiding Seminar Nasional 2016 Program Studi Pendidikan Matematika Universitas Madura, Madura. Hal. 1-11.

Dewita, A., Mujib, A., \& Siregar, H. (2019). Studi Etnomatematika tentang Bagas Godang sebagai Unsur Budaya Mandailing di Sumatera Utara. Mosharafa: Jurnal Pendidikan Matematika, 8(1), 1-12. DOI: https://doi.org/10.31980/moshar afa.v8i1.202

Mardiani, D. (2019). Model Accelerated Learning Cycle dalam Pembelajaran Pertidaksamaan Linear dan Nilai Mutlak. Mosharafa: Jurnal Pendidikan Matematika, 8(3), 483-492. DOI: https://doi.org/10.31980/moshar afa.v8i3.537

Puspitasari, N., Afriansyah E. A., Nuraeni, R., Madio, S. S., \& Margana, A. (2019). What are the difficulties in statistics and probability?. Journal of Physics: Conference Series, 1402(7), 077092.

Ridia, N. S., \& Afriansyah, E. A. (2019). Perbandingan

Kemampuan Pemahaman Matematis Siswa melalui Auditory Intellectualy Repetition dan Student Teams Achievement Division. Mosharafa: Jurnal Pendidikan Matematika, 8(3), 515-526. DOI: https://doi.org/10.31980/moshar afa.v8i3.509
Spradley, J.P. (2006). Metode Etnografi. Yogyakarta: Tiara Wacana.

Sugiyono. (2016). Metode Penelitian Kuantitatif, Kualitatif dan R\&D. Bandung: Alfabeta.

Supriono, P. (2016). Ensiklopedia The Heritage of BATIK Identitas Pemersatu Kebanggaan Bangsa. Yogyakarta: Andi Van De Walle, John A. (2008). Matematika Sekolah Dasar dan Menengah Jilid 1 Edisi Keenam. Terjemahan oleh Suyono. Jakarta: Erlangga.

Zayyadi, M. (2017). Eksplorasi etnomatematika pada batik madura. Jurnal Pendidikan Matematika SIGMA, 2(2).

\section{Riwayat Hidup Penulis}

Eva Mulyani, M.Pd.

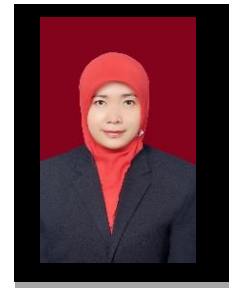

Lahir di Tasikmalaya, 20 Maret 1983. Staf pengajar di Universitas Siliwangi. Studi S1 Pendidikan Matematika Universitas Siliwangi, Tasikmalaya, lulus tahun 2005; S2 Pendidikan Matematika Universitas Terbuka, UPBJJ Bandung, lulus tahun 2014.

\section{Ike Natalliasari, M.Pd.}

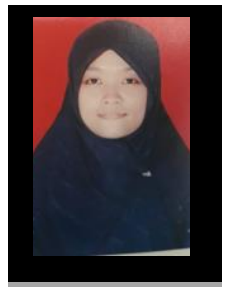
Lahir di Ciamis, 05 Desember 1980. Staf pengajar di Universitas Siliwangiu. Studi S1 Pendidikan Matematika Universitas Siliwangi, Kota Tasikmalaya, Lulus tahun 2003; S2 Pendidikan Matematjka Universitas Terbuka UPBJJ Bandung, Tahun lulus 2014. 